\title{
Von Schicksalsschlägen und Lebens(über)mut
}

\section{Isabel Zwyssig}

M.A., koordinierende Redaktorin

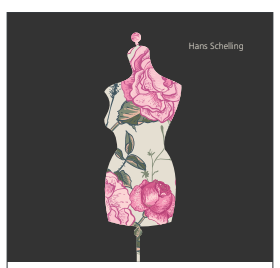

IM ROSENPARK G

Hans Schelling

Im Rosenpark Entwicklungsroman Bern: Einfach Lesen Verlag; 2014. 192 Seiten. 30.90 CHF. ISBN 978-3-952-40613-7
Nach Lupinenmehl. Ein launiger Minithriller aus dem Appenzell (2012 bei BoD) erschien im November 2014 der Entwicklungsroman Im Rosenpark, herausgegeben vom Verlag Einfach Lesen Bern. Zwar geht es in der zweiten Publikation von Hans Schelling, der seit seinem Medizinstudium Kurzgeschichten und Gedichte schreibt, nicht so mysteriös zu und her wie im Erstling. Allerdings ist auch Im Rosenpark ein gelungenes belletristisches Beispiel dafür, wie Menschen mit Schicksalsschlägen und den einschneidenden Veränderungen, die diese nach sich ziehen, umgehen lernen. Schellings Hauptfigur Marielouise, eine erfolgreiche Modejournalistin und Besitzerin der Ostschweizer Modeagentur Organza, wird im Verlaufe ihres Lebens mit verschiedenen Herausforderungen konfrontiert, die sie bisweilen an die Grenzen ihrer Belastbarkeit bringen, beinahe verzweifeln, aber auch triumphieren und dankbar auf Vergangenes zurückblicken lassen. Immer steht dabei der geistige und seelische Entwicklungsprozess im Vordergrund, den die Protagonistin in Auseinandersetzung mit sich selbst, ihren Mitmenschen und der Umwelt durchläuft. Hans Schelling beweist in seinem Roman eine feine Beobachtungsgabe für zwischenmenschliche Belange. Er lässt seine Figuren nahezu alle Emotionen erleben, die auf dem Barometer des menschlichen Empfindens vorkommen von unaussprechlicher Freude, tiefer Zuneigung und Harmonie über hohen Ehrgeiz bis hin zu grenzenloser Trauer und Wut. Der Arzt, der in der Berner Altstadt eine Praxis für Gesprächs- und Neuraltherapie führt, weiss um die Zerbrechlichkeit des Glücks. In ihrer Vielgestaltigkeit jedoch besitzt die menschliche Seele die Kraft, Leid zu ertragen und zu verarbeiten.

\section{Nach Verlusten einen Neuanfang wagen}

Ein Prozess, der im Entwicklungsroman Im Rosenpark geradezu leitmotivisch wiederkehrt. Marielouises Lebenszufriedenheit scheint vollkommen, als sie mit 23 Jahren den ambitionierten Zementfabrikanten Harald von Stockenberg heiratet und sich mit ihm in der Villa Im Rosenpark ein Zuhause für die gemeinsame Zukunft aufbaut. Das junge Paar widmet sich mit grosser Einsatzbereitschaft der beruflichen Karriere. Doch bald darauf machen Marielouise und Harald schmerzliche Verlusterfahrungen, die sie immer mehr voneinander entfernen. Nicht nur verliert Marielouise wegen vorzeitig einsetzender Blutungen ihr ungeborenes Kind. Auch Sohn Christian, der Jahre später zur Welt kommt, wird seinen Eltern viel zu früh durch einen tragischen Lawinenunfall entrissen. Marielouise und Harald hadern mit dem Schicksal, überschreiten Grenzen, entfremden sich voneinander, gehen Liebesbeziehungen mit anderen Partnern ein. Schritte in ein neues, erfüllteres Leben?

\section{Reflektierende Erzählweise schafft Nähe und Distanz}

Auch hier werden die Hauptfiguren von Verlassenheitsgefühlen begleitet, erleben Verzweiflung und schöpfen neuen Mut. Schellings reflektierende Erzählweise erlaubt es, Handlungen und innere Entwicklungen der Figuren aus Distanz zu betrachten. Sie schafft aber gleichzeitig die Möglichkeit, sich ein Stück weit mit der Erlebnisrealität der Protagonisten zu identifizieren. Manchmal freilich muten innere Zerrissenheit, leise Wehmut und Abgeklärtheit etwas überzeichnet, ja beinahe kitschig an. So etwa ganz zum Schluss des Romans, als Marielouise, versöhnt mit sich und ihrem bewegten Leben, in der idyllischen Geborgenheit ihrer Villa unter dem seligen Blick ihrer verstorbenen Haustiere Madame Pentecote, Luisli und Dagobert die Vision ihres Ex-Mannes ereilt, der lächelnd hinter den Bäumen hervortritt. Interessant wäre es ausserdem gewesen, zu erfahren, wie sich die Situation von Harald entwickelt hätte, wenn ihm der Autor ein anderes Schicksal auferlegt hätte... Erfrischend witzig, weil ironisch überhöht, wirkt die Figurenzeichnung der unverbesserlichen Ehrentraud Hilfiker, die an grenzenloser Selbstüberschätzung leidet. Hans Schelling verfasst mit seinem Entwicklungsroman Im Rosenpark eine Geschichte, wie sie das Leben schreiben könnte. Als Leser fühlt man mit den Protagonisten und wird zum Nachdenken über zentrale Fragen der menschlichen Existenz angeregt. Da verzeiht man dem Autor gerne den einen oder anderen stilistischen Patzer. 